Toncheva K. D., Korol D. M., Zaporozhchenko I. V., Kozak R. V., Tonchev M. D. The myogymnastics complex as an element of rehabilitation in the process of adaptation to orthopedic appliances in patients after stroke. Journal of Education, Health and Sport. 2021;11(04): 122-130. eISSN 2391-8306. DOI http://dx.doi.org/10.12775/JEHS.2021.11.04.013

https://apcz.umk.pl/czasopisma/index.php/JEHS/article/view/JEHS.2021.11.04.013

https://zenodo.org/record/4814662

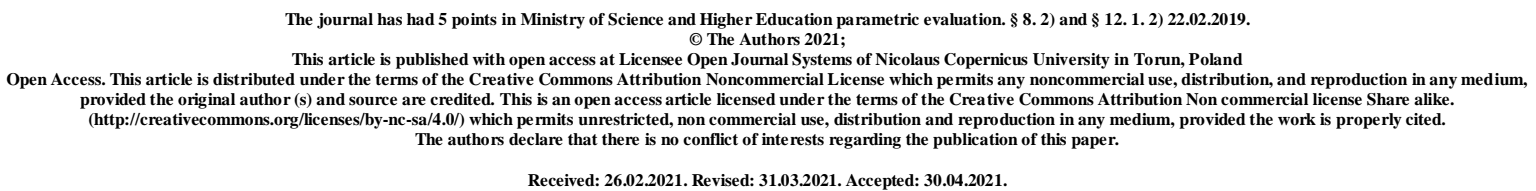

UDC 616.314-089.23-06:616.841-005.1]-044.352:615.825:81'342.3

\title{
THE MYOGYMNASTICS COMPLEX AS AN ELEMENT OF REHABILITATION IN THE PROCESS OF ADAPTATION TO ORTHOPEDIC APPLIANCES IN PATIENTS AFTER STROKE
}

\author{
K. D. Toncheva, D. M. Korol, I. V. Zaporozhchenko, R. V. Kozak, M. D. Tonchev
}

Poltava State Medical University

Toncheva KD - 0000-0003-2322-6056

Korol DM - 0000-0002-8331-0500

Zaporozhchenko IV - 0000-0001-5799-3232

Kozak RV - 0000-0002-7717-0935

Tonchev MD - 0000-0002-1994-4613

\section{Abstract}

Introduction. Stroke has become the second leading cause of long-term disability and cognitive impairment. The disease can cause debilitating neurological disorders that lead to motor, sensory and cognitive deficits and impaired psychosocial functioning. Many researchers have established an association between dental status, infections, and systemic diseases such as acute cerebrovascular disorder.

The aim of the research was to determine the impact of dental health on the quality of life in patients with cerebral circulatory disorders complicated with neurological deficits by hemitype before and 30 days after orthopedic treatment by questionnaire survey.

Materials and methods. The study involved 25 people with the course of ACVD complicated with neurological deficiency by hemitype, aged from 40 to 65 years, who 
underwent prosthetics with partial removable laminar dentures with acrylic base and retaining bent, metal clasps according to clinical indications. The first group, where the process of adaptation to the orthopedic appliance was normal, consisted of 13 people, including 7 women and 6 men. In the second group, the adaptation process took place using the proposed rehabilitation complex, and it comprised 12 patients, including 7 women and 5 men.

The changes that occurred 30 days after applying a partial removable laminar denture were as follows:

The value of the indicator of restricted masticatory function in subjects of the first study group was worse by 1.375 points as compared to the second group. The value of the indicator of physical pain in the process of adaptation to the orthopedic appliance was noteworthy, since it decreased significantly in the second group and amounted to 14.404 points, which was by 1.335 points higher than in patients of the first group.

The level of psychological discomfort in patients of the first group was 32.412 points, which was 1.183 points different from that of patients in the second group, in favor of the latter. At the same time, a comparison of the level of psychological inferiority showed that this indicator was higher in the first group than in the second study group by 0.988 points, i.e., the dynamics of changes in this indicator was better in the second one.

Comparison of the level of social inferiority showed that in the first study group it was higher by 2.106 points than in the third group. Comparison of the level of disability showed a difference of this indicator by 1.226 points in favor of patients of the second group

The above data suggest a general trend of improving the basic health indicators of patients in the process of orthopedic rehabilitation. At the same time, there was a clear difference between the results of the questionnaire survey between patients of the first and second groups, and these indicators were better in the latter.

Conclusions. The effectiveness of the proposed rehabilitation complex for patients with cerebral circulatory disorders complicated with neurological deficiency by hemitype after prosthetics with partial removable laminar appliances was confirmed by a decrease in numerical data from the questionnaire survey by $15 \%$, indicating an improvement in quality of life in this category of patients.

Key words: quality of life; stroke; dental status; orthopedic rehabilitation; questionnaires; myogymnastics. 
Introduction. Stroke has become the second leading cause of long-term disability and cognitive impairment. The disease can cause debilitating neurological disorders that lead to motor, sensory and cognitive deficits and impaired psychosocial functioning. Many researchers have established an association between dental status, infections, and systemic diseases such as acute cerebrovascular disorder (ACVD) [1 - 5].

It is believed that the unsatisfactory condition of the oral cavity can affect the general condition, whereas systemic diseases, in turn, can have manifestations in the oral cavity $[6,7$, 8]. In many foreign studies, the authors compared oral health in patients with stroke and apparently healthy population (control group) and found that patients with stroke had a lower level of oral health and were less likely to visit the dentist than the control group [9 - 13]. It should be emphasized that only a few studies have assessed the health of the oral cavity according to the functional levels of patients with stroke. The quality of rehabilitation of patients with ACVD can be assessed by the level of self-sufficiency achieved in daily activities $[14,15]$.

It is well known that rehabilitation after stroke is necessary as early as possible to improve the motor, cognitive and daily functions of such patients. Despite the established relationship between dental status and general somatic diseases, little is known about the need for cooperation between medical and dental professionals.

The aim of the research was to determine the impact of dental health on the quality of life in patients with cerebral circulatory disorders complicated with neurological deficits by hemitype before and 30 days after orthopedic treatment by questionnaire survey.

Materials and methods. The study involved 25 people with the course of ACVD complicated with neurological deficiency by hemitype, aged from 40 to 65 years, who underwent prosthetics with partial removable laminar dentures with acrylic base and retaining bent, metal clasps according to clinical indications. The first group, where the process of adaptation to the orthopedic appliance was normal, consisted of 13 people, including 7 women and 6 men. In the second group, the adaptation process took place using the proposed rehabilitation complex, and it comprised 12 patients, including 7 women and 5 men.

The rehabilitation plan of patients of the third study group relied on the myogymnastics complex based on therapeutic exercises by V.A. Yepifanov, A.V. Yepifanov (2020), G.A. Moroz, V.V. Vasilieva, N.M. Kulyk (2014) [17]. Patients were instructed as to the exercises on the day of applying a partial removable laminar denture, the appropriate control took place on days 7 and 30 of using the orthopedic appliance. The main condition for prescribing the complex was the mandatory visualization of training, i.e., the patient performed 
myogymnastic exercises in front of a mirror - with the effect of feedback, thus assessing the completeness and correctness of the tasks by the patient [17]. To facilitate the exercises, patients were asked to apply the target on a mirror (Fig. 1), and on the most protruding point of the chin - a patch as a marker to compare the marker and the main points of the target.

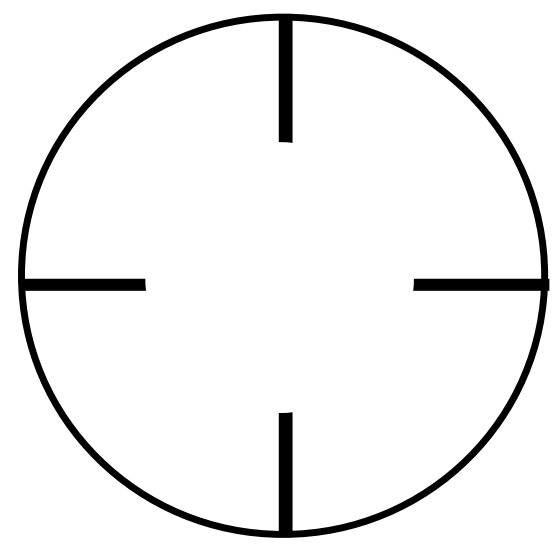

Fig. 1. The target for performing exercises

Physical exercises were divided into two stages. The first stage was performed 3 times a day 30 minutes before a meal.

1. Fold your lips into a tubule. Performing the exercise: Week 1 - for 1 minute, but not less than 15 times; Week 2 - for 2 minutes, but not less than 35 times; Week 3 - for 3 minutes, at least 50 times; Week 4 - for 5 minutes, but not less than 90 times.

2. Maximum displacement of the mandible to the right, left and forward. Performing the exercise: Week 1 - for 1 minute, but not less than 6 times; Week 2 - for 2 minutes, but not less than 15 times; Week 3 - for 3 minutes, at least 25 times; Week 4 - for 5 minutes, but not less than 45 times.

3. Circular movements of the mandible clockwise and counterclockwise. Performing the exercise: Week 1 - for 1 minute, but not less than 2 rotations in each direction; Week 2 for 2 minutes, but not less than 5 times in each direction; Week 3 - for 3 minutes, not less than 8 times; Week 4 - for 5 minutes, but not less than 12 circular motions in each direction.

The second stage was also performed 3 times a day, but to prevent complications from the gastrointestinal tract, 1 hour after a meal.

1. Alternate mastication of the chewing gum with menthol flavor on the right and left sides. Performing the exercise: Week 1 - for 2 minutes; Week 2 - for 3 minutes; Week 3 - for 4 minutes; Week 4 - for 5 minutes. 
2. Inflating an air bubble from the chewing gum. Algorithm of actions:

- The chewing gum should be chewed thoroughly to a soft, plastic state.

- Twist the gum into a ball with your tongue. Use the center of the tongue to hold the gum in place while you give it a rounded shape, not necessarily a perfectly rounded one.

- Place the ball behind the front teeth. Using your tongue and the back of your teeth, flatten the ball into a flat disk.

- Slowly and gently press the tip of the tongue on the middle of the disk, as if pulling the gum on the tongue. Slightly open your lips, continue to push your tongue until it is completely covered with a thin layer of the chewing gum. Be careful, because any careless movement can break the gum if it happens - just twist the chewing gum into a ball and start over.

- When the tip of the tongue is covered with a thin layer of chewing gum, fill it with air, forming a bubble. You should feel the air fill the gum and start pushing it out of your mouth.

- Pull the tongue out of the layer of chewing gum, keeping your mouth open, exhale slowly, inflating the bubble. Keep blowing as long as possible until it bursts.

- It is recommended to pre-moisten the lips with water before inflating the ball, so that the gum will not stick to the lips when it bursts.

Performing the exercise: Week 1 - for 2 minutes; Week 2 - for 3 minutes; Week 3 for 4 minutes; Week 4 - for 5 minutes.

After each set of exercises, the patient performed a slight self-massage of the masticatory muscles and the circular muscle of the mouth.

All representatives of the control and study groups gave free and informed consent to participate in the study, which was recorded in the protocols and certified by signatures.

To assess the impact of dental health on the quality of life of patients, a specific OHIP-49 questionnaire was used, which includes 49 questions divided into blocks and identifies functional limitations (questions 1-9), physical pain (questions 10-18), psychological discomfort (questions 19 -32), psychological inferiority (questions 33-38), social inferiority (questions 39-43) and disability (questions 44-49). The questionnaire provided 7 possible answers: I do not know (-), never (0), almost never (1), sometimes (2), often (3), very often (4), I do not use dentures (0). Each question of the questionnaire had a corresponding coefficient, the multiplication of which gave the appropriate numerical result. Adding the results in the block gave the sum of points for each indicator. 
The questionnaire survey was conducted during the first consultation visit, at the clinic of orthopedic dentistry. Re-survey took place on the 30th day after applying a partial removable laminar denture. All patients were informed about the protection of personal data obtained during the questionnaire survey.

Statistical processing of the obtained data was performed using the Statistica 10.0 software package for Windows. The selected level of significance of the possible error was 0.05 , i.e., the $5 \%$ possibility of deviation of the null hypothesis was assumed, and the significance of differences in values equaled to 0.95 or $95 \%$. The intergroup comparison of results was performed using the nonparametric Mann-Whitney method at different observation times.

Results of the research. The rate of limited masticatory function in the first group before orthopedic treatment was by 0.212 points lower than in patients of the second study group. Comparison of the values of physical pain before using the appliance showed a difference between the first and second groups of 0.736 points in favor of the latter.

Determination of indicators of psychological discomfort demonstrated almost the same level in both groups before prosthetics and amounted to 57.462 points in the first group and 57.447 - in the third group. The study of the level of psychological inferiority made it possible to identify the difference between the first and second groups of 0.757 points in favor of the first group.

Comparison of social inferiority in patients of both groups before orthopedic treatment revealed a difference of 0.138 points between the first and second groups, towards the second one. The level of disability of patients in the first group was 17.254 points, which is by 0.479 less than in representatives of the third group.

The changes that occurred 30 days after applying a partial removable laminar denture were as follows:

The value of the indicator of restricted masticatory function in subjects of the first study group was worse by 1.375 points as compared to the second group. The value of the indicator of physical pain in the process of adaptation to the orthopedic appliance was noteworthy, since it decreased significantly in the second group and amounted to 14.404 points, which was by 1.335 points higher than in patients of the first group.

The level of psychological discomfort in patients of the first group was 32.412 points, which was 1.183 points different from that of patients in the second group, in favor of the latter. At the same time, a comparison of the level of psychological inferiority showed that 
this indicator was higher in the first group than in the second study group by 0.988 points, i.e., the dynamics of changes in this indicator was better in the second one.

Comparison of the level of social inferiority showed that in the first study group it was higher by 2.106 points than in the third group. Comparison of the level of disability showed a difference of this indicator by 1.226 points in favor of patients of the second group (Table 1).

Table 1

Descriptive statistics of the results from the questionnaire survey of patients after stroke $(\mathrm{p}<0.05)$

\begin{tabular}{|c|c|c|c|c|c|}
\hline Characteristics & $\begin{array}{l}\text { Mean } \\
\text { Group } 1\end{array}$ & $\begin{array}{c}\text { Mean } \\
\text { Group } 2\end{array}$ & $\mathrm{U}$ & $\mathrm{Z}$ & p-value \\
\hline $\begin{array}{l}\text { Indicator of limited masticatory } \\
\text { function before applying the denture }\end{array}$ & 27.963 & 28.176 & 72.500 & -0.27196 & 0.785650 \\
\hline $\begin{array}{l}\text { Indicator of physical pain before } \\
\text { applying the denture }\end{array}$ & 28.069 & 27.333 & 60.500 & 0.92468 & 0.355134 \\
\hline \begin{tabular}{lcc} 
Indicator & of & \multicolumn{2}{c}{ psychological } \\
discomfort & before & applying the \\
denture & &
\end{tabular} & 57.462 & 57.447 & 77.000 & -0.02720 & 0.978303 \\
\hline 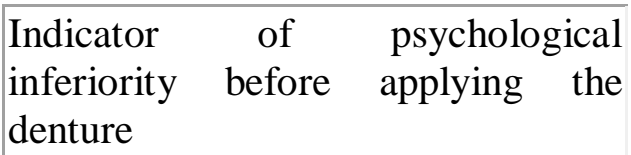 & 22.570 & 23.327 & 54.000 & -1.27823 & 0.201169 \\
\hline $\begin{array}{l}\text { Indicator of social inferiority before } \\
\text { applying the denture }\end{array}$ & 23.984 & 24.122 & 77.000 & 0.02720 & 0.978303 \\
\hline $\begin{array}{l}\text { Indicator of disability before } \\
\text { applying the denture }\end{array}$ & 17.254 & 16.775 & 67.500 & 0.54393 & 0.586491 \\
\hline $\begin{array}{l}\text { Indicator of limited masticatory } \\
\text { function } 30 \text { days after applying the } \\
\text { denture }\end{array}$ & 18.758 & 17.383 & 27.500 & 2.71964 & 0.006536 \\
\hline $\begin{array}{l}\text { Indicator of physical pain } 30 \text { days } \\
\text { after applying the denture }\end{array}$ & 15.739 & 14.404 & 30.500 & 2.55646 & 0.010575 \\
\hline $\begin{array}{l}\text { Indicator } \quad \text { of } \\
\text { discomfort } 30 \text { days after applying } \\
\text { the denture }\end{array}$ & 32.412 & 31.229 & 38.500 & 2.12132 & 0.033896 \\
\hline $\begin{array}{l}\text { Indicator of } \quad \text { psychological } \\
\text { inferiority } 30 \text { days after applying the } \\
\text { denture }\end{array}$ & 14.911 & 13.923 & 39.000 & 2.09412 & 0.036250 \\
\hline $\begin{array}{l}\text { Indicator of social inferiority } 30 \\
\text { days after applying the denture }\end{array}$ & 13.927 & 11.821 & 33.500 & 2.39328 & 0.016699 \\
\hline $\begin{array}{l}\text { Indicator of disability } 30 \text { days after } \\
\text { applying the denture }\end{array}$ & 13.068 & 11.832 & 41.000 & 1.98534 & 0.047108 \\
\hline
\end{tabular}


Thus, the above data suggest a general trend of improving the basic health indicators of patients in the process of orthopedic rehabilitation. At the same time, there was a clear difference between the results of the questionnaire survey between patients of the first and second groups, and these indicators were better in the latter.

Conclusions. The effectiveness of the proposed rehabilitation complex for patients with cerebral circulatory disorders complicated with neurological deficiency by hemitype after prosthetics with partial removable laminar appliances was confirmed by a decrease in numerical data from the questionnaire survey by $15 \%$, indicating an improvement in quality of life in this category of patients.

Prospects for further research are to explore the possibilities of using the proposed complex of myogymnastic exercises with additional involvement of biological feedback devices.

\section{References}

1. Gerreth P, Gerreth K, Maciejczyk M, Zalewska A, Hojan K. Is an Oral Health Status a Predictor of Functional Improvement in Ischemic Stroke Patients Undergoing Comprehensive Rehabilitation Treatment? Brain Sci. 2021;11(3):338.

2. Sen S., Giamberardino L.D., Moss K., Morelli T., Rosamond W.D., Gottesman R.F., Beck J., Offenbacher S. Periodontal Disease, Regular Dental Care Use, and Incident Ischemic Stroke. Stroke. 2018;49:355-362.

3. Yoshida M., Murakami T., Yoshimura O., Akagawa Y. The evaluation of oral health in stroke patients. Gerodontology. 2012;29:489-493.

4. Meurman J.H. A Role for Oral Health Personnel in Stroke Prevention. Compend. Contin. Educ. Dent. 2017;38(Suppl. 8):26-28.

5. Toncheva K. D. Neobkhidnist' ortopedychnoyi reabilitatsiyi khvorykh z insul'tom pry nevrolohichnomu defitsyti po hemitypu u vidnovnomu periodi. Aktual'ni problemy suchasnoyi medytsyny. 2018; 18,2(62):282-7. [Ukrainian]

6. Dietrich T., Webb I., Stenhouse L., Pattni A., Ready D., Wanyonyi K.L., White S., Gallagher J.E. Evidence summary: The relationship between oral and cardiovascular disease. Br. Dent. J. 2017;222:381-385.

7. Zoellner H. Dental infection and vascular disease. Semin. Thromb Hemost. 2011;37:181-192.

8. Toncheva, K., Korol, D., Tonchev, M., Kozak, R., Zaporozhchenko, I. Diahnostyka porushen' roboty zhuval'nykh m"yaziv ta kolovoho $\mathrm{m}^{\prime \prime}$ yaza rota $\mathrm{u}$ patsiyentiv $\mathrm{z}$ insul'tom 
(klinichnyy vypadok). The Medical and Ecological Problems. 2020;24(1-2), 44-48. [Ukrainian]

9. Lafon A., Pereira B., Dufour T., Rigouby V., Giroud M., Béjot Y., Tubert-Jeannin S. Peridontal disease and stroke: A met-analysis of cohort studies. Eur. J. Neurol. 2014;21:1155-1161.

10. Fagundes N.C.F., Almeida A.P.C.P.S.C., Vilhena K.F.B., Magno M.B., Maia L.C., Lima R.R. Periodontitis as a risk factor for stroke: A systematic review and meta-analysis. Vasc. Health Risk Manag. 2019;15:519-532.

11. Zeng L.N., Rao W.W., Luo S.H., Zhang Q.E., Hall B.J., Ungvari G.S., Chen L.G., Xiang Y.T. Oral health in patients with stroke: A meta-analysis of comparative studies. Top Stroke Rehabil. 2020;27:75-80.

12. Dai R., Lam O.L., Lo E.C., Li L.S., Wen Y., McGrath C. A systematic review and meta-analysis of clinical, microbiological, and behavioural aspects of oral health among patients with stroke. J. Dent. 2015;43:171-180.

13. Ajwani S., Jayanti S., Burkolter N., Anderson C., Bhole S., Itaoui R., George A. Integrated oral health care for stroke patients-A scoping review. J. Clin. Nurs. 2017;26:891901.

14. Shiraishi A., Yoshimura Y., Wakabayashi H., Tsuji Y., Shimazu S., Jeong S. Impaired oral health status on admission is associated with poor clinical outcomes in postacute inpatients: A prospective cohort study. Clin. Nutr. 2019;38:2677-2683.

15. Kim H.T., Park J.B., Lee W.C., Kim Y.J., Lee Y. Differences in the oral health status and oral hygiene practices according to the extent of post-stroke sequelae. J. Oral Rehabil. 2018;45:476-484.

16. Yepifanov V.A., Yepifanov A.V. Meditsinskaya reabilitatsiya pri zabolevaniyakh i povrezhdeniyakh chelyustno-litsevoy oblasti. Moskva: GEOTAR Meditsina; 2020. 76 s. [Russian]

17. Toncheva K.D., Korol D.M., Tonchev M.D. Perspektyvy vykorystannya biolohichnoho zvorotnoho zv"yazku v shchelepno-lyts'oviy dilyantsi v protsesi reabilitatsiyi khvorykh z uskladnenym perebihom hostroho porushennya mozkovoho krovoobihu. Endovaskulyarna neyrorenthenokhirurhiya. 2018;3:76-81. [Ukrainian] 